\title{
A 11-year-old boy with oral submucous fibrosis: A rare case report
}

0
0
0
5
0
0
$\frac{1}{1}$

\section{Shivesh Kumar, Abhinav Srivastava, Chander Mohan, Mukta Pagrani}

Department of Ear, Nose, and Throat, Rohilkhand Medical College, Bareilly,

Uttar Pradesh, India

Address for the Correspondence:

Dr. Abhinav Srivastava,

Department of Ear, Nose, and

Throat, Rohilkhand Medical

College and Hospital, Pilibhit bypass Road, Bareilly - 243 006, Uttar Pradesh, India.

E-mail: drabhinav.srivastava@ yahoo.co.in

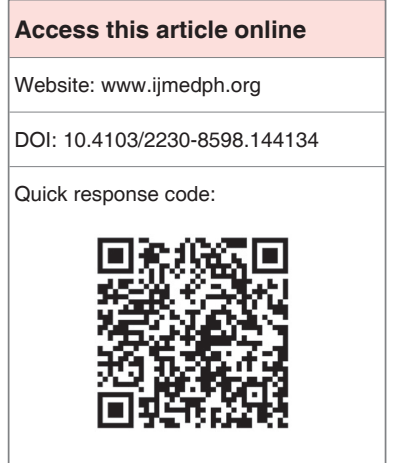

Oral submucous fibrosis is a chronic debilitating disorder, which is usually seen in adults with areca nut quid chewing habit. A rapid upsurge in the popularity of commercial areca nut quid products, especially among the younger generation, is a cause of grave concern, as satisfactory management is still lacking. A case of oral submucous fibrosis in an 11-year-old boy is presented along with histopathological findings, highlighting strong association of areca nut chewing as the potential factor in the etiology of this condition.

Key words: Areca nut quid, oral submucous fibrosis, pouch culture

\section{INTRODUCTION}

Oral submucous fibrosis (OSMF) is a chronic disorder characterized by progressive fibrosis of the lining mucosa of the oral cavity, oropharynx, and frequently the upper third of the esophagus, resulting in intolerance to spicy foods, a burning sensation in the mouth, xerostomia, and limitation of mouth opening, tongue mobility, swallowing or phonation.

It mostly occurs in Asian countries, where chewing Areca nut quid (AQ: contains areca nut, tobacco, slaked lime, and other spices) and other commercial preparations of areca nut quid in attractive pouches is popular. ${ }^{[1]}$ Epidemiologic surveys in India show the rate of prevalence to be about $0.5 \%$. Persons between 20 and 40 years of age are most commonly affected with a female: male ratio of 3:1. ${ }^{[2]}$ Morbidity of OSMF among AQ users is about $3.2 \%$, and it has a malignant transformation rate in the range of $7-13 \% .^{[3]}$

The pathogenesis of the disease is not well established, but is believed to be multifactorial. Various mechanisms suggested include:

a. Clonal selection of fibroblasts with a high amount of collagen production during long-term exposure to areca nut,

b. Stabilization of collagen structure by catechin and tannins from AQ,

c. Production of stable collagen (type I) by OSF fibroblasts,

d. Increase in collagen cross-linking by upregulation of lysyl oxidase,

e. Deficient collagen phagocytosis, and

f. micronutrient and vitamin deficiencies. ${ }^{[4]}$

OSMF is uncommon in the pediatric age group. Only limited number of pediatric cases have been reported in the literature, youngest being a 4-year-old girl ${ }^{[5]}$ and in other two reports 9 and 11 years old girls have been reported. ${ }^{[6,7]}$ A Pediatric case of OSMF is reported, highlighting the potential danger of involvement of the pediatric age group from "pouch culture".

\section{CASE REPORT}

An 11-year-old boy brought by his parents to the department of ENT with complaint of inability to open the mouth and burning sensation in mouth since last two months. There was a history of eating 5-6 packets of sweet supari per day for the last one year. There was no information on the packet of sweet supari about the contents of the packet, as it appears that there must be other addictive constitutions apart from supari, which compelled the child to continue taking the product for 1 year. 
General physical examination was normal. On Oral examination, there was reduced inter-incisor distance (IID) of $1.5 \mathrm{~cm}$, there were generalized tobacco stains on teeth and hard palate with decreased elasticity and generalized blanched oral mucosa [Figure 1]. A punch biopsy from the oral mucosa was taken and sent for histopathological examination. Microscopic picture with H\&E stain shows chronic inflammatory reaction and sub-epidermal fibrosis with focal atrophy to hyperplasia with fibroblastic change of lamina propria [Figure 2, Low and High Power). On MTS stain, there was fibrosis involving muscles, which were replaced by blue colored collagen [Figure 3]. PAS stain was negative for glycogen [Figure 4a] and Von Gleisson stain was negative for muscle [Figure 4b]. So, a diagnosis of OSMF was established on clinical basis, which was confirmed by different histopathological examination stains.

Patient along with his parents were counseled to immediately stop the usage of areca nut quid and its preparation, and was given triamcinolone paste for local application, Oral pentoxyphylline $100 \mathrm{mg}$ TDS for five weeks and oral multivitamin - antioxidants preparation and mouth-opening exercise for six months. At six month, though there was minimal improvement in mouth opening but there was marked improvement in complaint of burning sensation in mouth.

\section{DISCUSSION}

Oral submucous fibrosis is regarded as a collagen metabolic disorder with an overall increased collagen production and

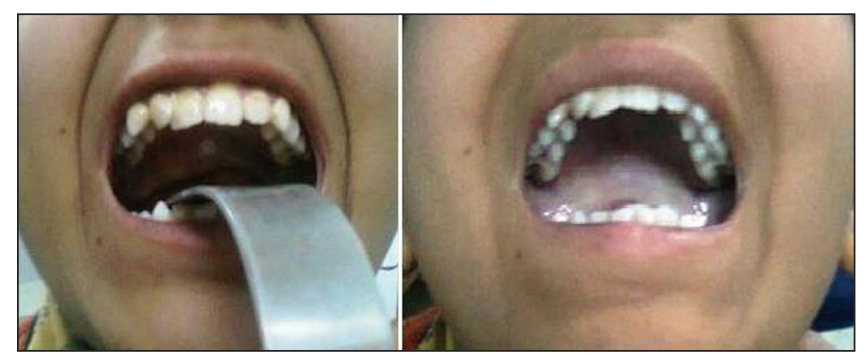

Figure 1: Picture showing reduced mouth opening with blanched oral mucosa

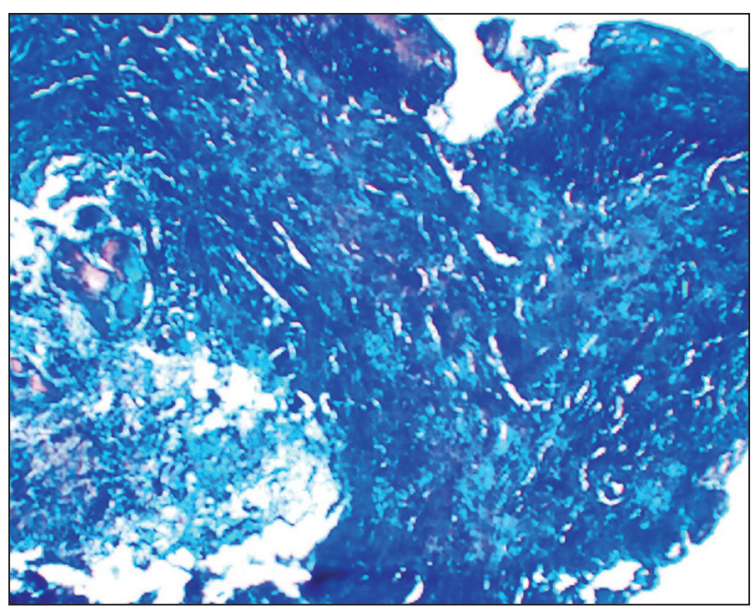

Figure 3: Microscopic picture of histological section (MTS Stain): Positive, thus favouring fibrosis decreased collagen degradation resulting in increased collagen deposition in the oral tissues, and fibrosis due to alkaloid exposure as a result of exposure to AQ.

Quid is defined as "a substance, or mixture of substances, placed in the mouth or chewed and remaining in contact with the mucosa, usually containing one or both of the two basic ingredients, tobacco and/or areca nut, in raw or any manufactured or processed form." Clear delineations on contents of the quid (areca nut quid, tobacco quid, and tobacco and areca nut quid) are recommended as absolute criteria with finer subdivisions to be added, if necessary. The betel quid refers to any quid wrapped in betel leaf and is therefore a specific variety of quid. ${ }^{[8]}$

Oral submucous fibrosis is seen predominantly in Asians who chew betel nut quid or its variants such as gutkha (mitha pan), kiwam, zarda and pan masala. Sweetened versions of betel nut quid are sold to children as sweet supari, gua, mawa or mistee pan. The easy availability of packaged dried product such as gutkha, is increasing the incidence of this condition, as it consists of a greater dry weight of areca nut quid along with other OSMF producing ingredients than the traditional quid rolled in betel leaf (paan). Only betel nut chewing does not cause OSMF, contribution of other ingredients like slaked lime is more important in the causation of OSMF. ${ }^{[9]}$

Oral submucous fibrosis can be seen at any age, but is rare in young children. The predominant age group affected is $20-40$ years. Compared to traditional betel nut quid, gutkha chewing tends to begin at a younger age and has a shorter time to the development of disease, so cases of OSMF have begun to appear in younger age group.

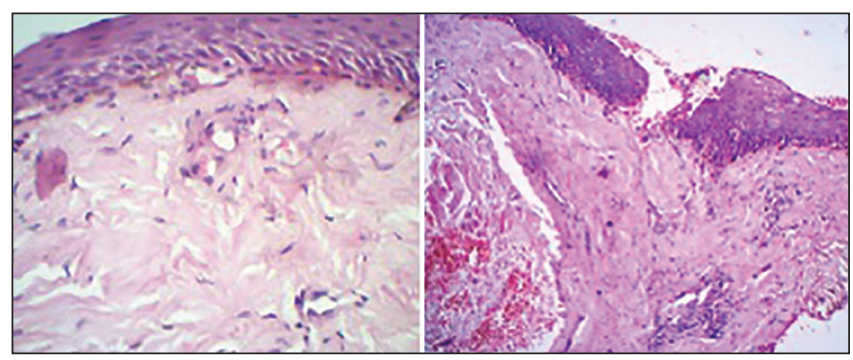

Figure 2: (Low and High Power) Microscopic picture of histological section (H\&E Stain) of OSMF lesion showing Subepidermal fibrosis with juxtaepidermal chronic inflammatory reaction

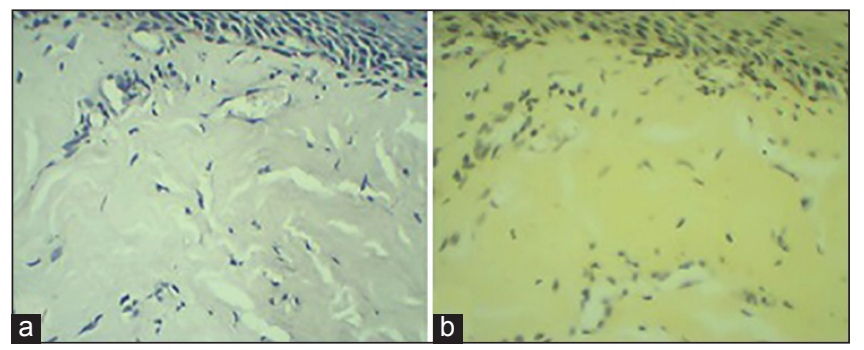

Figure 4: (a) PAS Stain negative for Glycogen, and (b) Von Gleisson Stain negative for muscle 
The list of treatment modalities is extensive. First and foremost is the behavior therapy to condition the subjects to stop this addiction. A wide variety of treatment modalities has been suggested, which include the use of micronutrients and minerals, $\mathrm{CO}_{2}$ laser, drugs like pentoxifylline, lycopene, interferon gamma, turmeric, hyalase, chymotrypsin, and placental extracts. As fibrosis cannot be reversed when mouth opening is severely reduced, surgical interventions such as myotomy, coronoidectomy, and excision of the fibrotic bands have also been reported in the literature. Alternatively, procedures such as insertion of stent, physiotherapy, local heat therapy, and mouth-opening exercises with acrylic carrots and ice-cream sticks have been tried with variable success rates..$^{[10,11]}$

Till today, no well-established treatment for OSMF exists and approaches using injections of steroids, chymotrypsin, hyaluronidase, or alcohol, and surgery using mucosal or non-vascularized split thickness grafts have not only been ineffective but have also often exacerbated the condition, with added scar tissue. ${ }^{[12]}$

\section{CONCLUSION}

There is a close relationship between areca-nut chewing and the development of OSMF. The present drug treatments are empirical and symptomatic in nature. So, there is no certain cure for the condition, just training and prevention seem to be the only way to reduce the risk of OSMF. In the near future, younger ones may be affected more and an active preventive approach is required to limit the morbidity associated with the modern pouch culture.

\section{REFERENCES}

1. Murti PR, Bhonsle RB, Gupta PC, Daftary DK, Pindborg JJ, Mehta FS. Etiology of oral submucous fibrosis with special reference to the role of areca nut chewing. J Oral Pathol Med 1995;24:145-52.

2. Jayanthi V, Probert CS, Sher KS, Mayberry JF. Oral submucous fibrosis: A preventable disease. Gut 1992;33:4-6.

3. Mcgurk M, Craig GJ. Oral submucous fibrosis: Two case of malignant transformation in Asian immigrants to the United Kingdom. $\mathrm{Br} \mathrm{J}$ Oral Maxillofac Surg 1984;22:55-64.

4. Trivedi CR, Craig G, Warnakulasuriya S. The oral health consequences of chewing areca nut. Addict Biol 2002;7:115-25.

5. Hayes PA. Oral Submucous fibrosis in a 4-year-old girl. Oral Surg Oral Med Oral Pathol 1985;59:475-8.

6. Agrawal A, Airen Sarkar P, Shigli A. Oral Submucous fibrosis in a 9-year old Indian girl. BMJ Case Rep 2011;2011.

7. Shaha B, Lewis MA, Bedi R. Oral Submucous fibrosis in a 11-year-old Bangladeshi girl living in the United Kingdom. Br Dent J 2001;191:130-2.

8. Zain RB, Ikeda N, Gupta PC, Warnakulasuriya S, van Wyk CW, Shrestha P, et al. Oral mucosal lesions associated with betel quid, areca nut and tobacco chewing habits: consensus from a workshop held at Kuala Lumpur, Malaysia, November 25-27, 1996. J Oral Pathol Med 1999;28:1-4.

9. Sarode SC, Mahuli A, Sarode GS, Mahuli S. Why only areca nut chewing cannot cause oral submucous fibrosis? Med Hypothesis 2013;81:47-9.

10. Jiang $\mathrm{X}, \mathrm{Hu} \mathrm{J}$. Drug treatment of oral submucous fibrosis. A review of literature. J Oral Maxillofac Surg 2009;67:1510-15.

11. Marx RE, Stern D. Oral and Maxillofacial Pathology. A rationale for diagnosis and treatment. $1^{\text {st }}$ ed. Illinois: Quintessence publishing; 2003. p. 317-9.

12. Fedorowicz Z, Chan Shh-Yen E, Dorri M, Newton T, Shi L. Lack of reliable evidence for oral submucous fibrosis treatments. Evid Based Dent 2009;10:8-9.

How to cite this article: Kumar S, Srivastava A, Mohan C, Pagrani M. A 11-year-old boy with oral submucous fibrosis: A rare case report. Int J Med Public Health 2014;4:511-3.

Source of Support: Nil, Conflict of Interest: None declared. 